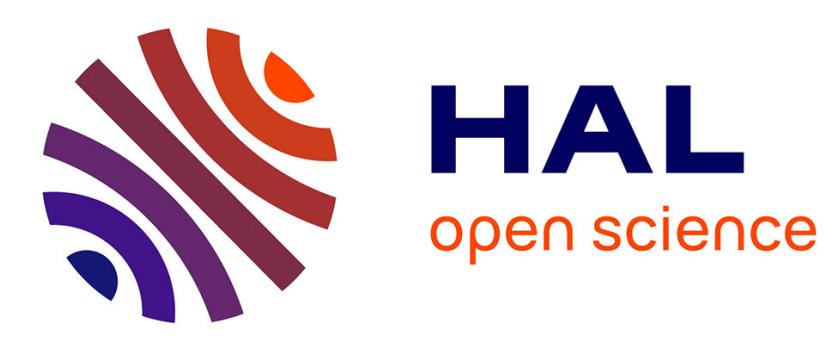

\title{
Tuning the oxidation states of dopants: a strategy for the modulation of material photoluminescence properties
}

Estelle Glais, Florian Massuyeau, Romain Gautier

\section{To cite this version:}

Estelle Glais, Florian Massuyeau, Romain Gautier. Tuning the oxidation states of dopants: a strategy for the modulation of material photoluminescence properties. Chemistry - A European Journal, 2020, 10.1002/chem.202003074 . hal-02993330

\section{HAL Id: hal-02993330 \\ https://hal.science/hal-02993330}

Submitted on 13 Nov 2020

HAL is a multi-disciplinary open access archive for the deposit and dissemination of scientific research documents, whether they are published or not. The documents may come from teaching and research institutions in France or abroad, or from public or private research centers.
L'archive ouverte pluridisciplinaire HAL, est destinée au dépôt et à la diffusion de documents scientifiques de niveau recherche, publiés ou non, émanant des établissements d'enseignement et de recherche français ou étrangers, des laboratoires publics ou privés. 
Tuning the oxidation states of dopants: a strategy for the modulation of material photoluminescence properties

\section{Estelle Glais ${ }^{1}$, Florian Massuyeau ${ }^{1}$, Romain Gautier ${ }^{1 *}$}

${ }^{1}$ Université de Nantes, CNRS, Institut des Matériaux Jean Rouxel (IMN), F-44000 Nantes, France.

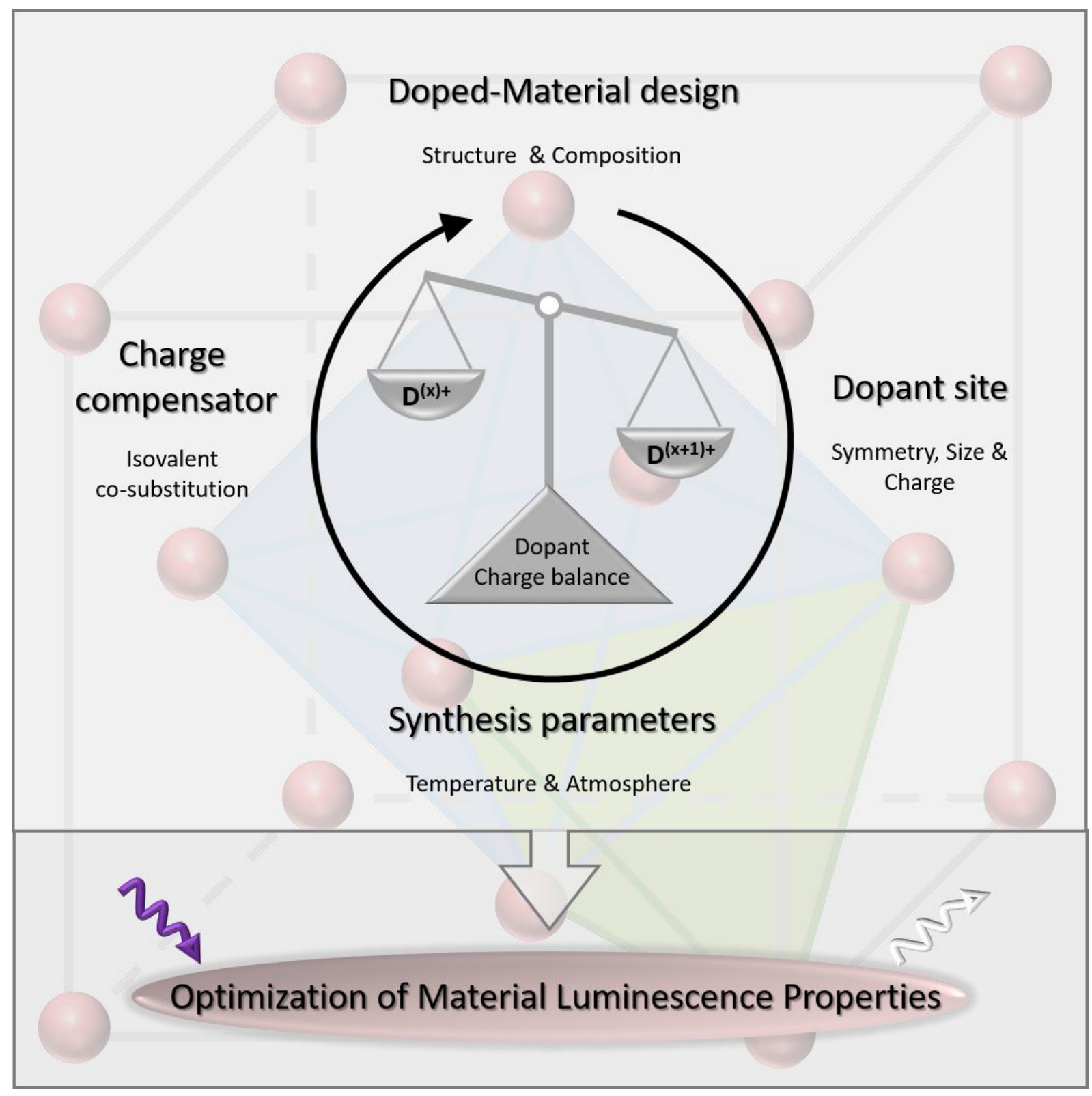




\begin{abstract}
Doped single-phase materials have been widely investigated owing to their easy to implement synthesis and the variety of their properties. This minireview covers strategies for the costabilization and the ratio control of several oxidation states of dopants inserted in the same host. The tuning of the oxidation states of dopants opens up many possibilities for the optimization of specific properties and can be envisioned for various applications such as telecommunication, medicine, display, lasers or lighting. Technics used for the quantification of each valence state of dopant are also emphasized, and the importance of high throughput methods for the discovery of competitive materials with dopant in multiple valence states is discussed.
\end{abstract}

\title{
1. Introduction
}

The development of new luminescent materials drawn a lot of interest over the past decades. Due to the high potential of their applications in various fields such as telecommunication, medicine, display, lasers or lighting, many studies have been focused on the understanding of luminescence processes and the optimization of luminescence properties ${ }^{[1,2]}$. Although the targeted properties vary according to the envisioned application, the material design is invariably a key parameter and is directly linked to the enhancement of the materials performances. In that respect, single phase luminescent inorganic materials have been widely investigated, since they can be synthesized using an easy-to-implement method, and open up a large variety of features.

The emitting range of a luminescent material is a fundamental specification for the targeted application. Thus, in bioimaging field, to prevent blood and water absorption as well as tissues autofluorescence and to limit the scattering, the emission wavelength range should be in the biological windows (BWI : 650 - $950 \mathrm{~nm}$ or BWII 1000 - $1350 \mathrm{~nm}$ ) ${ }^{[3]}$. Similarly, for white LEDs (w-LEDs) applications, a white light with tunable Color Correlated Temperature (CCT) is desired, while a NIR emission is required for telecommunication applications. There is a large choice of available phosphors emitting in different spectral regions, which allow to screen all the UV, visible or IR ranges. Since one emitting center can lead to multiple color emissions according to its environment sensitivity, the choice of the host matrix is crucial in order to reach the desired application.

Co-doped a material with several activators exhibiting emissions centered at specific wavelengths is a widely used approach to target the desired color of emission ${ }^{[4,5]}$. In this review, a specific strategy of co-doping, the control of the oxidation state of a single dopant, will be discussed. Many transition metal and rare earth ions can be stabilized in two oxidation states, both presenting 
specific luminescence properties in the visible or IR range, as for example $\mathrm{Mn}^{4+} / \mathrm{Mn}^{2+}, \mathrm{Ni}^{3+} / \mathrm{Ni}^{2+}$, $\mathrm{Bi}^{3+} / \mathrm{Bi}^{2+}, \mathrm{Eu}^{3+} / \mathrm{Eu}^{2+}, \mathrm{Tm}^{3+} / \mathrm{Tm}^{2+}$, or $\mathrm{Yb}^{3+} / \mathrm{Yb}^{2+}{ }^{[6-9]}$. Thus, the stabilization and the control of each valence states of dopant, could lead to the optimization of the luminescence properties ${ }^{[10-13]}$. However, the coexistence of several oxidation states of the same element in the matrix is not guaranteed, and can only occurs if specific conditions are encountered. ${ }^{[14]}$.As previously mentioned by Pei et al., the following requirements need to be considered during the material pre-design: i) No oxidizing (or reducing) ions should be present in the host material. ii) The charge balance is a key parameter. Thus for a given crystallographic site, a dopant $D$ should replace a host $\mathrm{H}^{\mathrm{x}+}$ or $\mathrm{H}^{(\mathrm{x}+1)+}$, to favor the stabilization of dopant reduced form $D^{(x)+}$ or oxidized form $D^{(x+1)+}$, respectively. iii) The dopant and the substituted cation must have similar ionic radii. iv) The crystallographic site of the host structure should be appropriate to ensure the dopant stabilization. In that respect, the resulting challenge is to identify suitable host matrices and compatible luminescent centers, combined with relevant synthesis conditions, that allow the co-stabilization of several oxidation states of dopant. In this review, the different strategies reported in the literature, enabling to stabilize and to modulate the contribution of each luminescent center with different valence states are detailed and illustrated through discussions on widely studied hosts such as $\mathrm{Y}_{3} \mathrm{Al}_{5} \mathrm{O}_{12}$ or $\mathrm{BaMgAl}_{10} \mathrm{O}_{17}$. Due to the low concentrations of dopants, the precise determination of their valence states remains challenging. The main characterization technics used to determine the valence states of dopants are highlighted in the second part of this review. Finally, the relevance of a high throughput screening for accelerating the discovery of material with dopants exhibiting multiple valence states is discussed.

\section{Approaches for the design of materials with dual valence states}

\subsection{Influence of synthesis atmosphere on the valence states of dopants}

Luminescent inorganic materials are commonly synthesized using high temperature processes. In such processes, the sintering atmosphere has a significant impact on the luminescence properties. One valence state of dopant can be preferentially stabilized at the expense of the other according to the partial pressure of oxygen. Thus a highly oxidative atmosphere such as $\mathrm{O}_{2}$ or air, will favor the stabilization of the oxidized form of dopant. On the contrary, with the use of a reductive atmosphere such as $\mathrm{CO}$ or $\mathrm{H}_{2}$, the reduced form of dopant will be predominantly stabilized. This has been demonstrated for example through the study of cerium-doped materials such as $\mathrm{Y}_{3} \mathrm{Al}_{5} \mathrm{O}_{12}$ : $\mathrm{Ce}$ and $\mathrm{Ca}_{3} \mathrm{Sc}_{2} \mathrm{Si}_{3} \mathrm{O}_{12}: \mathrm{Ce}^{[15-17]}$. Cerium is a rare earth element, which presents two stable oxidation states: $\mathrm{Ce}^{4+}$ and $\mathrm{Ce}^{3+}$. $\mathrm{Ce}^{4+}$ displays a $[\mathrm{Xe}] 4 \mathrm{f}^{0}$ electronic configuration, and is a non-luminescent center, except in the case of $\mathrm{O}^{2-} \rightarrow \mathrm{Ce}^{4+}$ charge transfer, while $\mathrm{Ce}^{3+}$ is a well-known luminescent center, with 
a $[X e] 4 f^{1}$ electronic configuration. $C e^{3+}$ emission originates from the $4 f^{1} \rightarrow 4 f^{0} 5 d^{1}$ transition (Figure 1a). Because of the $5 \mathrm{~d}$ levels involved in the transition, the $\mathrm{Ce}^{3+}$ emission wavelength drastically depends on the cation environment (e.g. crystallographic site, crystal field). For $\mathrm{Y}_{3} \mathrm{Al}_{5} \mathrm{O}_{12}: \mathrm{Ce}$ and $\mathrm{Ca}_{3} \mathrm{Sc}_{2} \mathrm{Si}_{3} \mathrm{O}_{12}: \mathrm{Ce}$, the $\mathrm{Ce}^{3+}$ emission band is centered respectively at 520 and $505 \mathrm{~nm}$. The photoluminescence $\left(\mathrm{PL}\right.$ ) intensity of $\mathrm{Ce}^{3+}$ emission is directly linked to the synthesis atmosphere (see Figure 1b). Thus, under oxidative atmosphere (in air), oxidation of $\mathrm{Ce}^{3+}$ ions into $\mathrm{Ce}^{4+}$ is favoured, which leads to the decrease of the luminescence intensity. In reductive atmosphere (CO), the ratio $\mathrm{Ce}^{3+} / \mathrm{Ce}^{4+}$ increases, improving the luminescence intensity. In $\mathrm{N}_{2}$ atmosphere, the material is isolated from any oxidative or reducing sources. Thus, an intermediate emission intensity corresponding to a limited stabilization of $\mathrm{Ce}^{3+}$ ions is observed. The charge balance is preserved owing to the formation (respectively filling) of oxygen vacancies in reducing (respectively oxidative) atmosphere. The study of $\mathrm{Ce}^{4+} / \mathrm{Ce}^{3+}$ doped materials illustrates the possibility of tuning the ratio of the dopant valence state according to synthesis conditions, which can be generalized to most of the dopants ${ }^{[18-20]}$.

a)

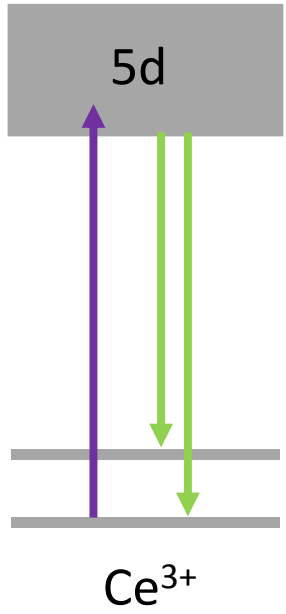

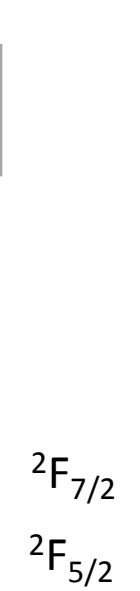

${ }^{2} \mathrm{~F}_{5 / 2}$

b)

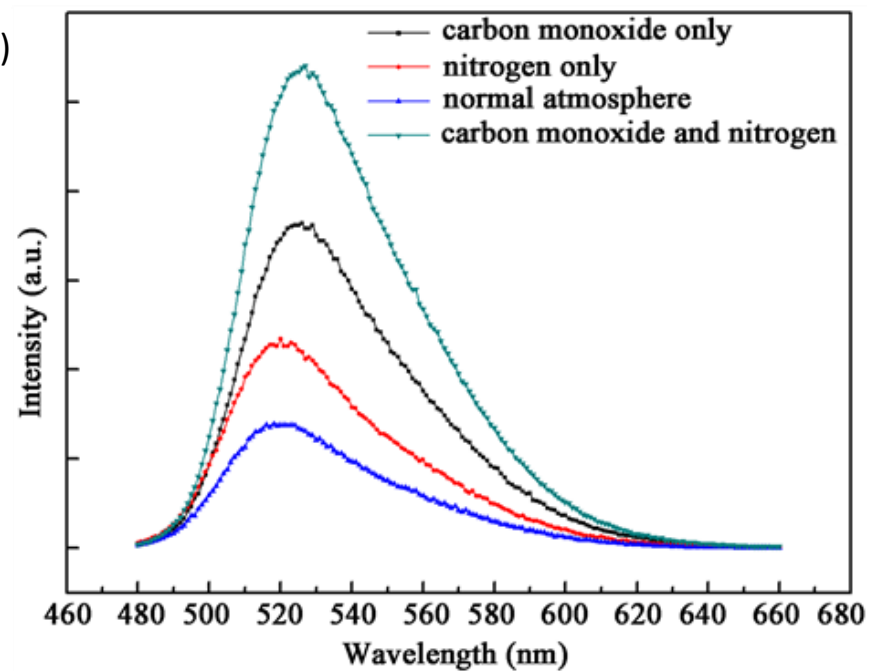

Figure 1: a) Schematic representation of $\mathrm{Ce}^{3+}$ energy levels b) Emission spectra of $\mathrm{Y}_{3} \mathrm{Al}_{5} \mathrm{O}_{12}: \mathrm{Ce}$ synthesized in different atmospheres. Reprinted with permission from Wang et al. ${ }^{[17]}$.

\subsection{The role of charge compensator in the stabilization of valence states}

Charge compensators (co-dopants) can play a significant role in the stabilization of specific valence states of activators. Such stabilization depends on many parameters such as the valence state of the charge compensator, their concentration or their stability in a specific host. Up to now, no general mechanism has been reported, but several hypotheses based on defect stabilisation are discussed. As stated previously, in luminescent inorganic phosphors, although dopants substitute preferentially cations of the crystal lattice with a similar ionic radius and same charge, substitutions of cations with different valence states can occur. Hence, the stability is provided by defects (namely 
anionic or cationic vacancies) or the introduction of interstitial ions ${ }^{[21]}$. In order to prevent defect formation, charge compensators can also be inserted inside the material. This strategy is widely investigated for preferential stabilization of one oxidation state of dopant, leading to the enhancement of luminescence properties. $\mathrm{Li}^{+}, \mathrm{Na}^{+}$, and $\mathrm{K}^{+}$are among the most widely used monovalent charge compensators ${ }^{[22-24]}$ but other multivalent charge compensators such as $\mathrm{Mg}^{2+}, \mathrm{Si}^{4+}$ or $\mathrm{Ge}^{4+}$ ions have also been investigated ${ }^{[25-28]}$. Many authors analysed the impact of charge compensator on photoluminescence properties. Thus, Zhu et al. ${ }^{[24]}$ highlighted the role of $\mathrm{Li}^{+}$as a charge compensator for $\mathrm{CaZr}_{4}\left(\mathrm{PO}_{4}\right)_{6}: \mathrm{Eu}$,Li materials. $\mathrm{Eu}^{3+}$ and $\mathrm{Eu}^{2+}$ ions can be both stabilized in 6coordinated $\mathrm{Ca}^{2+}$ sites, since all the different requirements outlined previously are fulfilled. To describe the phenomenon, a charge compensation mechanism has been proposed by Peng et al. ${ }^{[29]}$. In order to respect the charge balance, two $\mathrm{Eu}^{3+}$ ions should replace three $\mathrm{Ca}^{2+}$ ions. With $\mathrm{Li}^{+} \mathrm{co}-$ doping, the emission intensity ratio $\mathrm{I}\left(\mathrm{Eu}^{2+}\right) / I\left(\mathrm{Eu}^{3+}\right)$ decreases. Thus, $\mathrm{Li}^{+}$insertion implies the $\mathrm{Eu}^{3+}$ stabilization due to isovalent co-substitution of two $\mathrm{Ca}^{2+}$ by $\mathrm{Eu}^{3+}$ and $\mathrm{Li}^{+}$. In this case, the insertion of charge compensators leads to a better stability of the $\mathrm{Eu}^{3+}$ ions as well as an enhancement of the luminescence intensities. Furthermore, the $\mathrm{I}\left(\mathrm{Eu}^{2+}\right) / \mathrm{I}\left(\mathrm{Eu}^{3+}\right)$ ratio can be tuned by varying the concentration of $\mathrm{Li}^{+}$.

This phenomenon can be generalized for most of materials co-doped with charge compensators as it has been recently highlighted by $\mathrm{Xu}$ et al. ${ }^{[30]}$ through the study of $\mathrm{BaMgAl}_{10} \mathrm{O}_{17}: \mathrm{Mn}^{4+}, \mathrm{Mn}^{2+}$ (BAM:Mn) phosphors, co-doped with $\mathrm{Li}^{+}, \mathrm{Mg}^{2+}, \mathrm{Na}^{+}$and $\mathrm{Si}^{4+}$ ions. BAM: $\mathrm{Mn}^{4+}, \mathrm{Mn}^{2+}$ material presents an orderly layered structure in which spinel blocks $\mathrm{MgAl}_{10} \mathrm{O}_{16}$ are separated by non-doped $\mathrm{BaO}$ planes (mirror layers). Thus, $\mathrm{Mg}^{2+}$ ions are located in tetrahedral sites, whereas $\mathrm{Al}^{3+}$ ions occupy both tetrahedral and octahedral sites (see Figure $2 \mathrm{~b}$ ). $\mathrm{Mn}^{4+}$ is a $3 \mathrm{~d}^{3}$ ion and presents a red emission (originating from the spin forbidden ${ }^{2} \mathrm{E} \rightarrow{ }^{4} \mathrm{~T}_{2}$ transition). The $\mathrm{Mn}^{2+}$ ion presents a $3 \mathrm{~d}^{5}$ configuration. Its emission is crystal field dependent (from green to red according to the matrix and the coordination of the site in which it is inserted) ${ }^{[31-35]}$. In BAM host, $\mathrm{Mn}^{4+}$ ions are preferentially inserted in octahedral sites and exhibit a strong red emission centered at $660 \mathrm{~nm}$, whereas $\mathrm{Mn}^{2+}$ emission band is centered at $514 \mathrm{~nm}$ corresponding to the ${ }^{4} \mathrm{~T}_{1} \rightarrow{ }^{6} \mathrm{~A}_{1}$ transition (tetrahedral environment). According to the synthesis conditions, the intensity ratio between the two emission bands can significantly vary, but a more accurate ratio control can be achieved owing to the insertion of charge compensators. Thus, $\mathrm{Li}^{+}, \mathrm{Na}^{+}$or $\mathrm{Mg}^{2+}$ co-doping ( $\mathrm{Al}^{3+}$ substitution) leads to hole type defect formation, resulting in the stabilization of $\mathrm{Mn}^{4+}$ ions and the increase of their emission intensity at the expense of $\mathrm{Mn}^{2+}$ one (Figure 2). The most significant increase is obtained owing to $\mathrm{Mg}^{2+}$ doping. The formation of $\mathrm{Mn}^{4+}-\mathrm{Mg}^{2+}$ pairs, as presented in Figure $2 \mathrm{~b}$, maintains the charge balance and prevents the formation of $\mathrm{Mn}^{4+}-\mathrm{Mn}^{4+}-\mathrm{O}^{2-}$ clusters, which could induce non radiative processes. 
Similarly, $\mathrm{Si}^{4+}$ doping increases the emission intensity of $\mathrm{Mn}^{2+}$ at the expense of $\mathrm{Mn}^{4+}$ emission intensity. Since isovalent co-substitution of $\mathrm{Mn}^{4+}-\mathrm{Mg}^{2+}$ or $\mathrm{Mn}^{2+}-\mathrm{Si}^{4+}$ for $\mathrm{Al}^{3+}-\mathrm{Al}^{3+}$ improves the stability and the enhancement of the luminescence properties of $\mathrm{Mn}^{4+}$ and $\mathrm{Mn}^{2+}$ respectively, the intensity ratio between the two valence states of cations can be tuned according to the selected co-dopant.
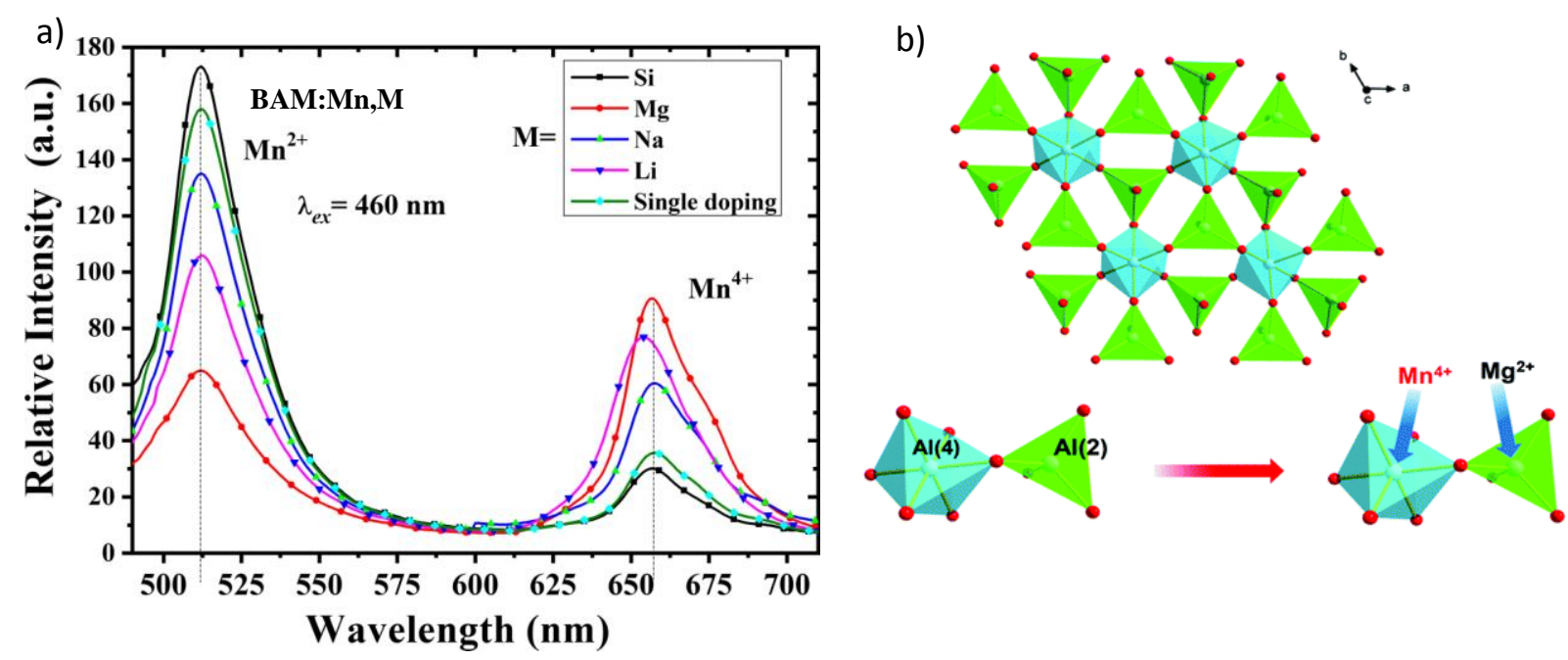

Figure 2: a) Photoluminescence spectra of $\mathrm{BAM}: \mathrm{Mn}^{4+}, \mathrm{Mn}^{2+}$ co-doped with different charge compensators $\left(\mathrm{Si}^{4+}, \mathrm{Mg}^{2+}, \mathrm{Na}^{+}, \mathrm{Li}^{+}\right)$b) Schematic representation of $\mathrm{BaMgAl}_{10} \mathrm{O}_{17}$ crystal structure and associated $\mathrm{Al}^{3+}$ ions substitution by $\mathrm{Mn}^{4+}$ ion and $\mathrm{Mg}^{2+}$ ions in octahedral and tetrahedral sites respectively. Reprinted with permission from Xu et al. ${ }^{[26]}$ and Hu et al. ${ }^{[19]}$.

However, the main issue of such approach is to find suitable charge compensator, to be inserted in the investigated host matrices.

\subsection{Gradual reduction/oxidation of dopants controlled by temperature}

After the synthesis, a thermal treatment at low temperature under oxidizing or reducing atmosphere could lead to the change of the valence state of dopants. As specified previously, the charge equilibrium is governed by oxygen vacancies formation or filling. The main issue is to finely control the ratio of dopant in their oxidized/reduced state and tune their photoluminescence properties. To this end, modulation of the thermal post-treatment parameters (temperature or duration) can be considered. In that context, Chen et al. [36] reported the study of $\mathrm{Sr}_{1.5} \mathrm{Ca}_{0.5} \mathrm{SiO}_{4}: \mathrm{Eu}^{3+}, \mathrm{Tb}^{3+}, \mathrm{Eu}^{2+}$ material, that exhibits luminescence properties with red, green and blue contributions owing to $\mathrm{Eu}^{3+}$ and $\mathrm{Tb}^{3+} 4 \mathrm{f} \rightarrow 4 \mathrm{f}$ and $\mathrm{Eu}^{2+} 4 \mathrm{f}^{6} 5 \mathrm{~d}^{1} \rightarrow 4 \mathrm{f}^{7}$ transitions respectively. The phosphor is synthesized in air, and in a second step annealed in reducing atmosphere. The $\mathrm{Eu}^{3+} / \mathrm{Eu}^{2+}$ ratio is tuned according to the duration of the second treatment $(15,30,45$ or $60 \mathrm{~min})$. The resulting emission spectra are presented in Figure 3a. In this work, the optimal duration of reducing process is 
$30 \mathrm{~min}$. For this duration, photoluminescence intensities of both emitters $\mathrm{Eu}^{3+}$ and $\mathrm{Eu}^{2+}$ are comparable. Thereafter, the doping concentration of $\mathrm{Tb}^{3+}$ ions is adjusted in order to reach the nearest value of $\mathrm{CIE}$ coordinates for an ideal white light $(0.321,0.322)$.

Controlled reduction of dopant can also be performed using oxygen getter such as hydrides (e.g. $\left.\mathrm{CaH}_{2}, \mathrm{NaH}, \mathrm{LiH}\right)$ as reducing agent ${ }^{[9,37-39]}$. This method can be implemented after material synthesis if the dopants are the only reducible elements in the material. It consists in the thermally activated disinsertion of oxygen from the crystal structure of the phosphor. Disinserted oxygen can then react with the getter to form thermodynamically stable oxides. Consequently, the dopants are reduced to keep the charge balance. Since this process is temperature and time dependent, it is possible to accurately control the valence states of dopants as it has been demonstrated by Behrh et al. ${ }^{\text {[38] }}$ through the investigation of $\mathrm{SrAl}_{2} \mathrm{O}_{4}$ :Eu phosphor (Figure 3b). The reduction of $\mathrm{Eu}^{3+}$ ions into $\mathrm{Eu}^{2+}$ is performed with $\mathrm{CaH}_{2}$ as oxygen getter. With the increase of reduction temperature, the $\mathrm{Eu}^{2+}$ emission intensity increases at the expense of $\mathrm{Eu}^{3+}$ emission intensity. Precise control of the dopant valence state can be achieved owing to the progressive reduction of $\mathrm{Eu}^{3+}$ into $\mathrm{Eu}^{2+}$, allowing to tune the resulting color of the phosphor from green to red. This gradual reduction of dopants (GRD) is a promising method to synthesize a single-phase white phosphor with desired resulting color, since it enables to optimize with a high accuracy the ratio between the two oxidation states of dopants. Nevertheless, since a small modification of one parameter of the post-annealing treatment leads to significant changes in luminescence properties, a large amount of samples is needed to discover the
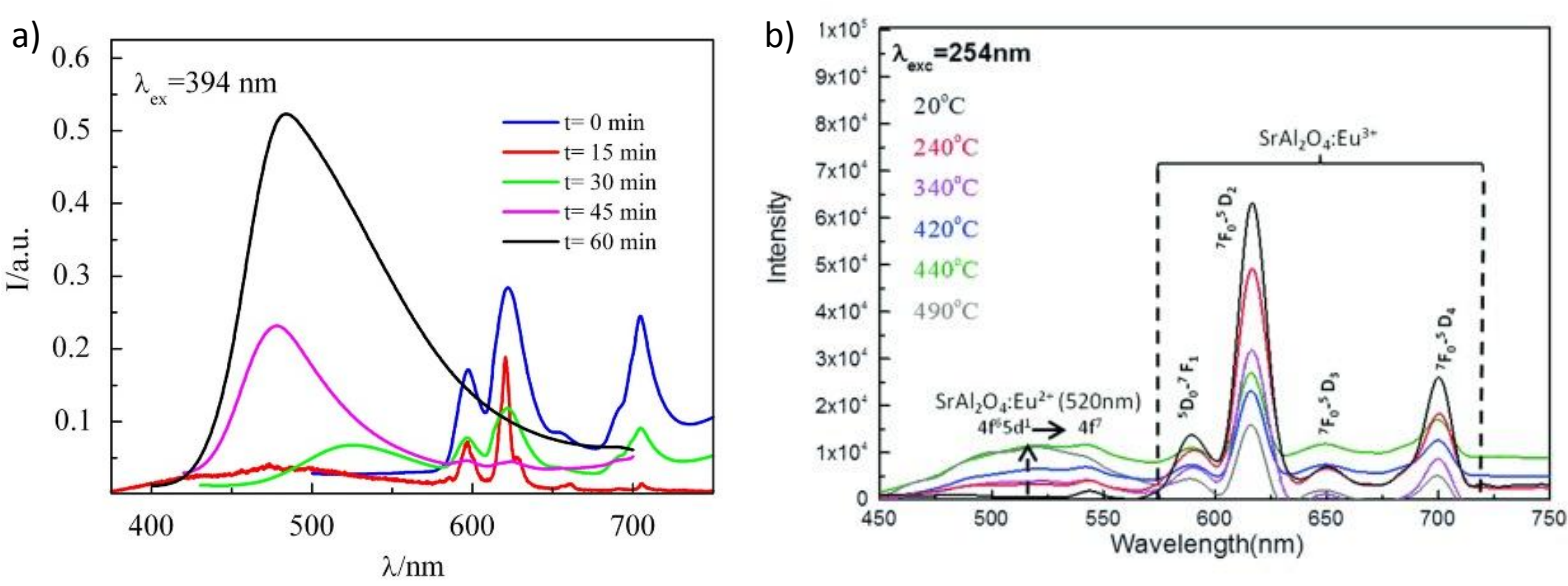

Figure 3: Emission spectra of a) $\mathrm{Sr}_{1.5} \mathrm{Ca}_{0.5} \mathrm{SiO}_{4}: \mathrm{Eu}^{3+}, \mathrm{Eu}^{2+}$ material post-annealed in reducing atmosphere at $1200^{\circ} \mathrm{C}$ during various b) $\mathrm{SrAl}_{2} \mathrm{O}_{4}: \mathrm{Eu}^{3+}, \mathrm{Eu}^{2+}$ material post-annealed in reducing atmosphere at various temperature during $96 \mathrm{~h}$. Reprinted with permission from Chen et ${ }^{a l}{ }^{[36]}$ and Behrh et al. ${ }^{[38]}$.

material with optimal properties. 


\subsection{Solid solutions for the stabilization of several oxidation states of a dopant}

Synthesizing solid solutions or nanosegregated phases is another approach to explore the stabilization of several valence states of a dopant. One oxidation state of dopant can be preferentially stabilized in a given environment. Hence, tuning the solid solution composition leads to the control of valence states distribution of the inserted dopant and thus to the modulation of the properties. For example, for (1-x) $\mathrm{Ba}_{0.75} \mathrm{Al}_{11} \mathrm{O}_{17.25}-\mathrm{x} \mathrm{BaMgAl}_{12} \mathrm{O}_{17}$ solid solution [19], the photoluminescence spectra are composed of two distinct contributions corresponding to $\mathrm{Mn}^{2+}$ (green emission) and $\mathrm{Mn}^{4+}$ (red emission) ions. As reported in Figure 4, the contribution of both ions varies according to the composition of the solid solution. This method is efficient to probe the interdependence of material crystal structure and oxidation state of dopant, and can also be coupled to the gradual reduction/oxidation method detailed previously. In such case, two parameters can be controlled, i.e. the composition of the solid solution and the oxidation state of dopant, leading to the

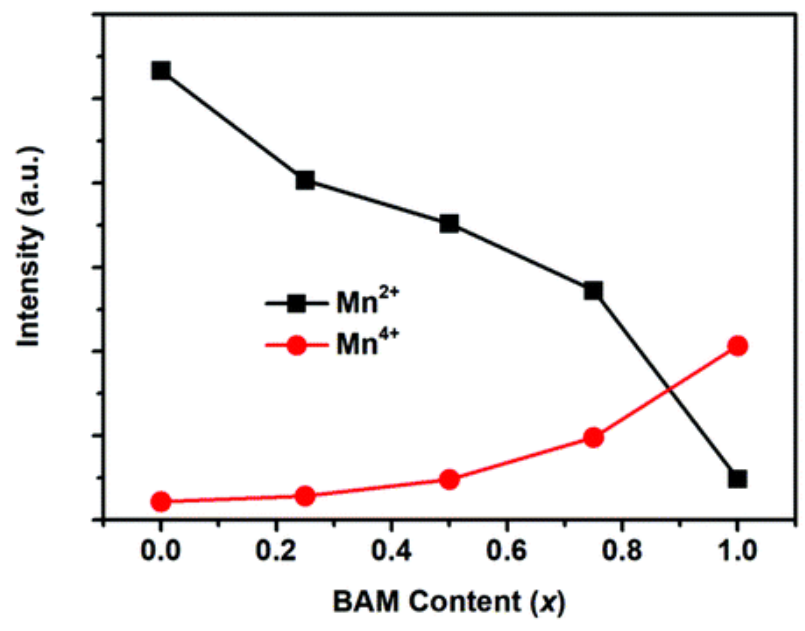

Figure 4: Variation of Photoluminescence intensity of $\mathrm{Mn}^{2+}$ (green contribution) and $\mathrm{Mn}^{4+}$ (red contribution) of (1-x) $\mathrm{Ba}_{0.75} \mathrm{Al}_{11} \mathrm{O}_{17.25}-\mathrm{x} \mathrm{BaMgAl}_{12} \mathrm{O}_{17}$ solid solutions, $\lambda_{\text {exc }}=424 \mathrm{~nm}$. Reprinted with permission from Hu et al. [19]

screening of the properties. 


\section{Influence of the excitation wavelength on the resulting photoluminescence properties}

The resulting emission color of a single-phase phosphor can typically be tuned according to the excitation wavelength. The emitting range and the emission intensity can vary depending on the excitation source and the energy levels of the emitting center involved in the luminescence process. For materials doped with several activators, excitation parameters can significantly influence the emission. Since each luminescent center exhibits specific excitation characteristics, the optimal emission intensity is not likely to be reached at the same excitation wavelength for all activators. For this reason, the ratio of emission intensities attributed to different activators depends on the excitation wavelength (see Figure 6a). Therefore, the emitting range and the associated CIE coordinates can significantly be tuned (Figure $6 b$ ). Thus, the optimization of luminescence properties can also be performed through the control of excitation parameters ${ }^{[40,41]}$. Sokolniki et al. ${ }^{[42]}$ and Martínez et al. ${ }^{[43]}$ investigated the tunning of emission color for $\mathrm{Sr}_{2} \mathrm{Y}_{8}\left(\mathrm{SiO}_{4}\right)_{6} \mathrm{O}_{2}: \mathrm{Eu}$ and $\mathrm{Y}_{2} \mathrm{Si}_{2} \mathrm{O}_{7}: \mathrm{Eu}$, respectively. In both phosphors, two valence states of europium are stabilized: $\mathrm{Eu}^{3+}$ and $\mathrm{Eu}^{2+}$. $\mathrm{Eu}^{3+}$ is a $4 f^{6}$ ion, its luminescence originates from $4 f \rightarrow 4 f$ transitions and is then scarcely influenced by the ion environment (Figure 5a). In these silicate hosts, the $\mathrm{Eu}^{3+}$ excitation spectra are composed of a broad

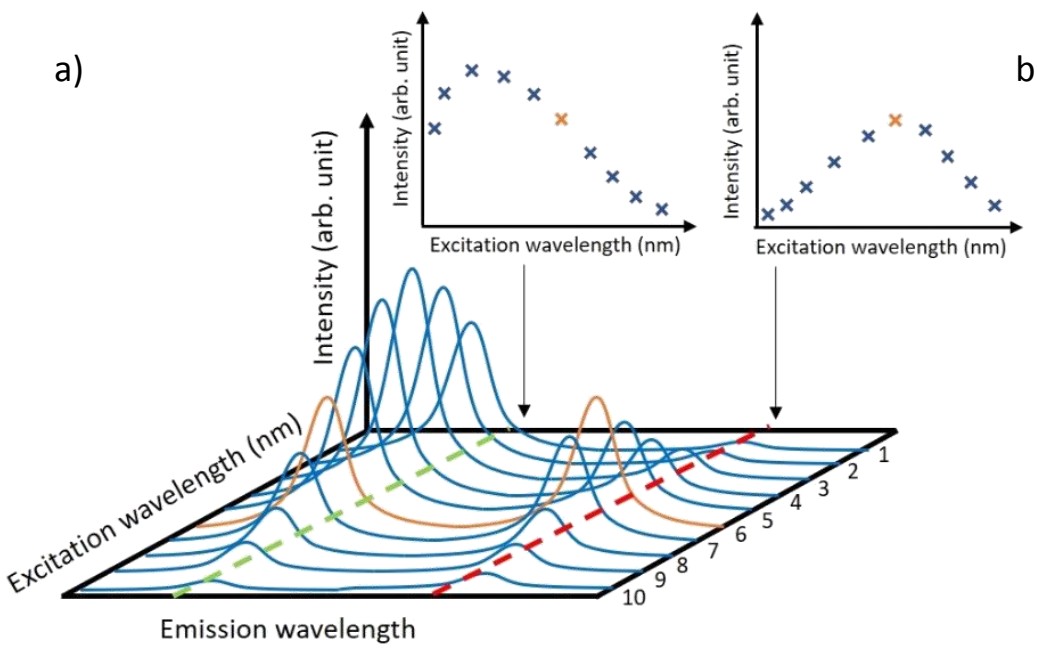

b)

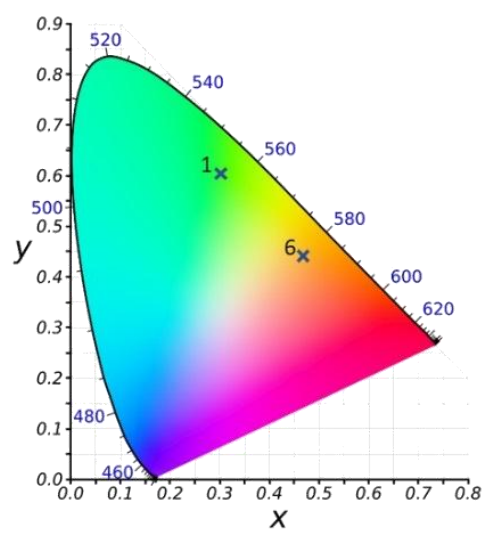

Figure $5:$ a) Schematic representation of a 3D excitation and emission photoluminescence spectra and b) associated CIE diagram.

band centered at $260 \mathrm{~nm}$ attributed to $\mathrm{O}^{2-} \rightarrow \mathrm{Eu}^{3+}$ charge transfer transition and several sharp peaks attributed to $4 \mathrm{f}$ transitions from 350 to $475 \mathrm{~nm}$. The $\mathrm{Eu}^{3+}$ red emission is assigned to ${ }^{5} \mathrm{D}_{0} \rightarrow{ }^{7} \mathrm{~F}_{\mathrm{J}}(\mathrm{J}=0$, $1,2,3,4)$ transitions. The $\mathrm{Eu}^{2+}$ excitation spectrum is composed of one broad band $\left(4 \mathrm{f}^{7} \rightarrow 4 \mathrm{f}^{6} 5 \mathrm{~d}^{1}\right.$ transition) shifted to higher wavelength compared to $\mathrm{Eu}^{3+}$ charge transfer band. The emission spectrum is also composed by one broad band assigned to the $4 f^{6} 5 d^{1} \rightarrow 4 f^{7}$ transition (Figure $5 b$ ). 
Due to the d levels involved in the radiative processes, the luminescence properties of $\mathrm{Eu}^{2+}$ ions are strongly crystal fields dependent. In the silicate hosts $\mathrm{Sr}_{2} \mathrm{Y}_{8}\left(\mathrm{SiO}_{4}\right)_{6} \mathrm{O}_{2}$ and $\mathrm{Y}_{2} \mathrm{Si}_{2} \mathrm{O}_{7}$, the emission

a)

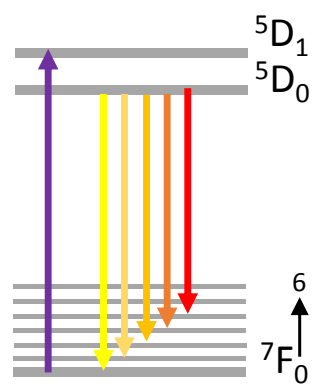

$\mathrm{Eu}^{3+}$ b)

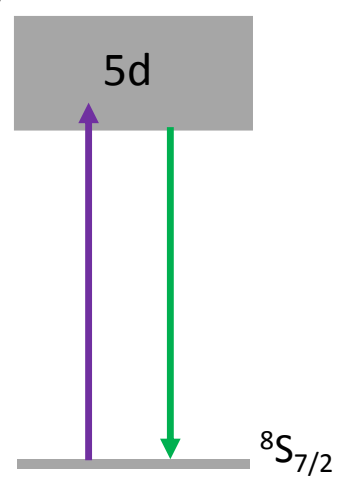

$\mathrm{Eu}^{2+}$

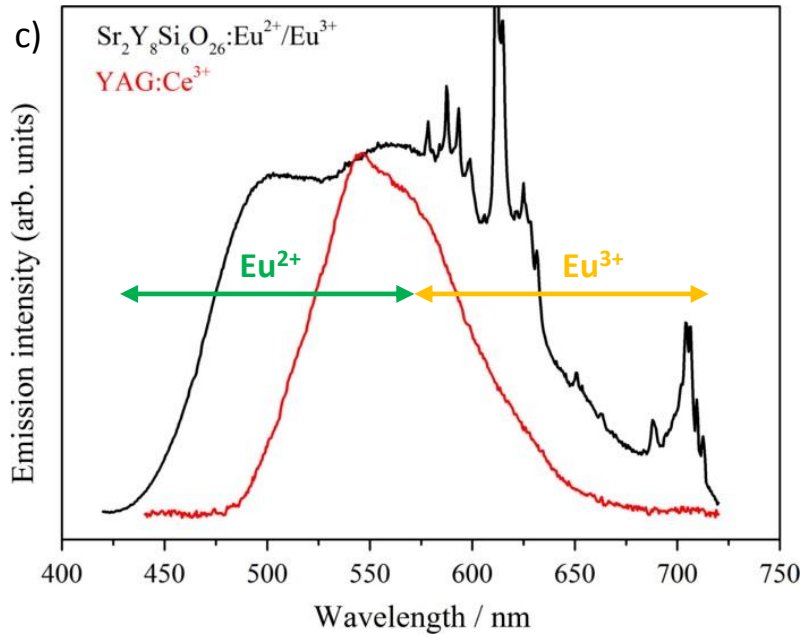

Figure 6 : Schematic representation of energetic levels and associated transitions of a) $\mathrm{Eu}^{3+}$ ion b) $\mathrm{Eu}^{2+}$ ion c) Photoluminescence emission spectra of $\mathrm{Sr}_{2} \mathrm{Y}_{8}\left(\mathrm{SiO}_{4}\right)_{6} \mathrm{O}_{2}$ :Eu material (black, $\lambda_{\text {exc }}=380 \mathrm{~nm}$ ) and YAG: $\mathrm{Ce}^{3+}\left(\mathrm{red}, \lambda_{\mathrm{exc}}=450 \mathrm{~nm}\right)$. Reprinted with permission from Sokolnicki et al. ${ }^{[42]}$.

broad band is centered at around $500 \mathrm{~nm}$, leading to a green contribution. At the appropriate excitation wavelength, emissions from both $\mathrm{Eu}^{2+}$ and $\mathrm{Eu}^{3+}$ ions in the green and red ranges can be obtained resulting in a larger covering of the visible range than the most widely used phosphor for wLEDs application : YAG:Ce ${ }^{3+}$ (Figure 5c). Thus, these silicate phosphors are very promising for such application since they provide CIE coordinates close to the standard white light and a high CRI (Color Rendering Index) up to 89. However, the best performances for LEDs application are not systematically reached at the optimized wavelengths.

\section{Quantification of the valence state of dopants}

It is important to note that it is not possible to precisely quantify the ratio of two oxidation states of one dopant using the photoluminescence properties only. Thus, the efficiencies of excitation and emission of activators depends strongly on many parameters including the excitation wavelength (see associated section), or absorption cross-section. Energy and charge transfers can also occur between ions, as well as non-radiative deexcitations (e.g. multiphonon relaxations via lattice vibration), leading to the variation of luminescence properties of emitting centers. Thus, in order to identify and quantify different oxidation states of dopant, several methods can be considered among which Electron Paramagnetic Resonance (EPR), X-ray Photoelectron Spectroscopy (XPS), or X-ray Absorption Near Edge Spectroscopy (XANES). 
Electron Paramagnetic Resonance (EPR) spectroscopy allows the identification of paramagnetic dopants including $\mathrm{Mn}^{2+}, \mathrm{Mn}^{4+}, \mathrm{Cr}^{3+}, \mathrm{Yb}^{3+}, \mathrm{Ce}^{3+}$ or $\mathrm{Eu}^{2+}$ ions ${ }^{[44-49]}$. Nevertheless, this characterization technique is limited since it can only provide a comparison of the dopants concentrations between samples by comparing the intensity of EPR signals. For instance, in the EPR spectra presented on Figure 7, the signal is characteristic of $\mathrm{Mn}^{2+}$ ion and its intensity variation is qualitatively linked to the
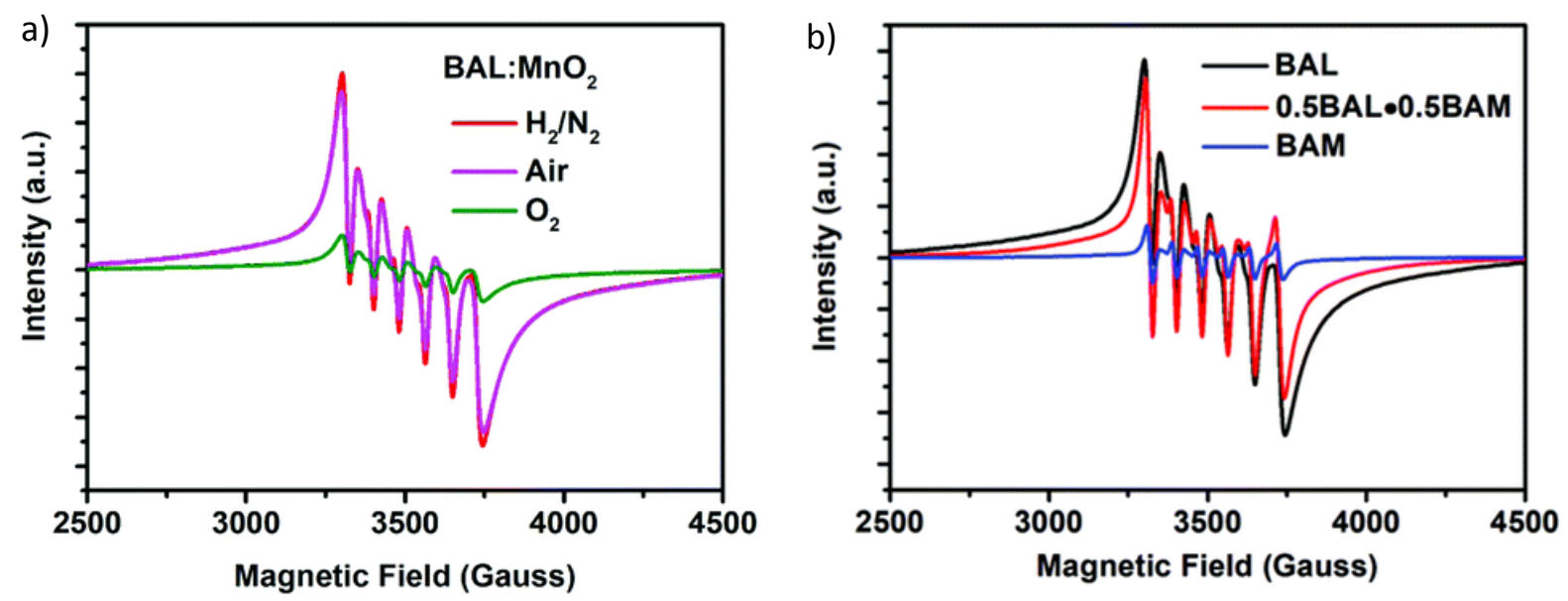

Figure 7: $\mathrm{Mn}^{2+}$ EPR spectra with six characteristic hyperfine transitions of several samples a) $\mathrm{Ba}_{0.75} \mathrm{Al}_{11} \mathrm{O}_{17.25}: \mathrm{Mn}^{2+}$ synthesized in different atmospheres b) $\mathrm{Mn}$ doped (1-x) $\mathrm{Ba}_{0.75} \mathrm{Al}_{11} \mathrm{O}_{17.25}-\mathrm{x}$ $\mathrm{BaMgAl}_{12} \mathrm{O}_{17}$ solid solutions with $\mathrm{x}=0,0.5$ and 1 . Reprinted with permission from Hu et al. ${ }^{[19]}$.

$\mathrm{Mn}^{2+}$ concentrations. Hence, Hu et al. ${ }^{[19]}$ highlighted the variation of $\mathrm{Mn}^{2+}$ doping ion concentration in i) $\mathrm{Ba}_{0.75} \mathrm{Al}_{11} \mathrm{O}_{17.25}$ host according to the synthesis condition (Figure 7a) ii) (1-x) $\mathrm{Ba}_{0.75} \mathrm{Al}_{11} \mathrm{O}_{17.25}-\mathrm{x}$ $\mathrm{BaMgAl}_{12} \mathrm{O}_{17}$ solid solution sample with various $\mathrm{x}$ values (Figure $7 \mathrm{~b}$ ). Chen et al. ${ }^{[50]}$ and Murata et al. ${ }^{[51]}$ demonstrated the $\mathrm{Mn}^{4+}$ stabilization owing to $\mathrm{Mg}^{2+}$ charge compensator introduction in $\mathrm{LaAlO}_{3}: \mathrm{Mn}^{4+}, \mathrm{Mg}^{2+}$ and $\mathrm{CaAl}_{12} \mathrm{O}_{19}: \mathrm{Mn}^{4+}, \mathrm{Mg}^{2+}$. Thus, the EPR spectra analysis allows not only to identify the magnetic species inserted in the material but also to construe the luminescence properties variation. Beside the identification and relative quantification, EPR spectroscopy also provides specifications on the material structure and on the local environment of the probing ion. ${ }^{[33,45,46]}$ 
X-ray Photoelectron Spectroscopy (XPS) is an efficient tool to probe the composition of a material as well as the valence state of inserted ions. This technic allows a precise quantification of the concentration of an element. Nevertheless, the doping concentration of luminescent center is very often below its detection threshold. Moreover, XPS is a surface characterization technique with a probing depth of about $10 \mathrm{~nm}$. Even when the dopant ions are randomly distributed in the material, the investigated volume is not always representative of the bulk. Several groups have performed XPS analysis to characterize samples doped with $\mathrm{Ce}^{[17,52]}, \mathrm{Eu}^{[24,53,54]}$, or $\mathrm{Mn}^{[30,55]}$ ions. Due to the typically low concentration of dopants, an absolute quantification of each oxidation state of dopant is, in most cases, not possible. XPS spectra analysis of such sample still provides many information such as i) the identification of each element inserted in the matrix, ii) the evidence of different oxidation states for a dopant, and iii) the relative ratios of concentrations.

X-ray Absorption Spectroscopy (XAS) is a powerful method for the investigation of structural and electronic properties. While EXAFS (Extended X-ray Absorption Fine Structure) provides information on atom environment $t($ bond lengths, neighbouring element, ...), the X-ray Absorption Near Edge Spectroscopy (XANES) region is related to local atomic states. Thus, the identification and precise quantification of each valence state of a dopant can be carried out ${ }^{[56-61]}$. In that respect, Avci et al. [56] reported the investigation of Eu-doped $\mathrm{CaAl}_{2} \mathrm{O}_{4}$ material. Both $\mathrm{Eu}^{2+}$ and $\mathrm{Eu}^{3+}$ signatures are highlighted on XANES spectra (see Figure 8), as well as the variation of the valence distribution

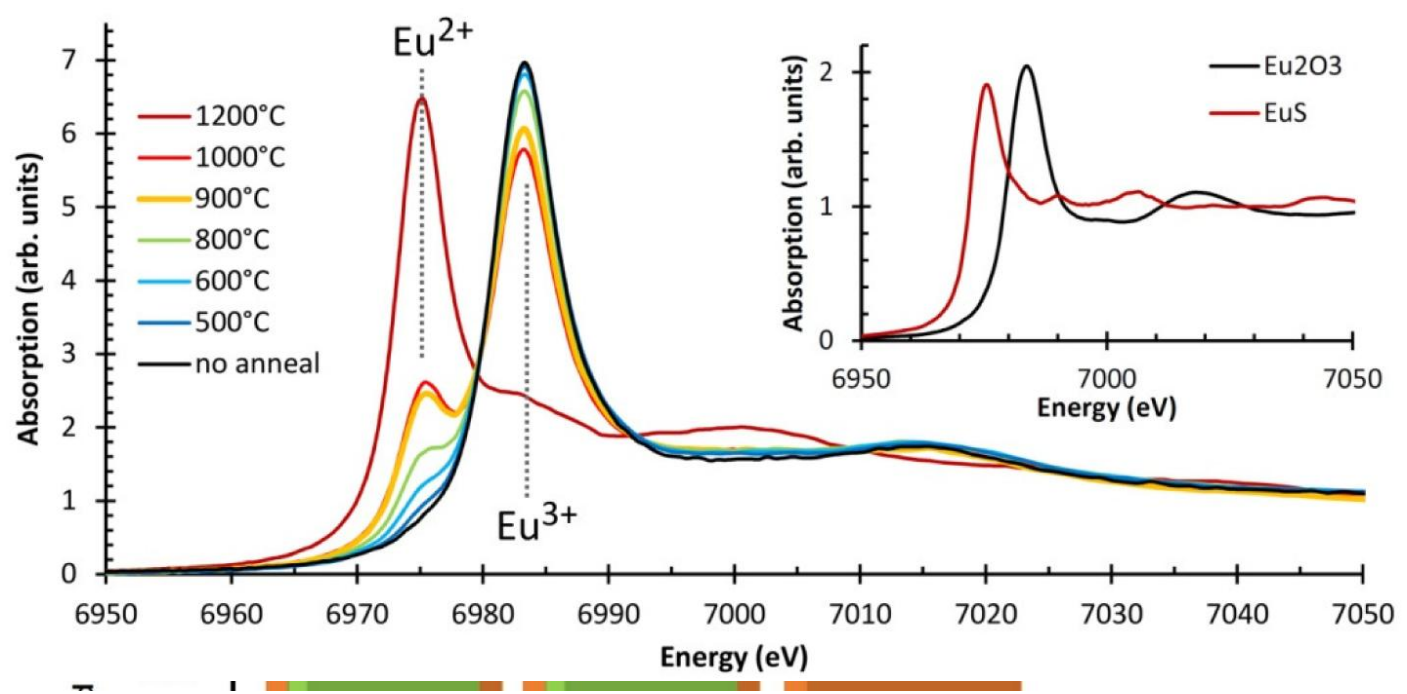

Figure 8: XANES spectra of $\mathrm{CaAl}_{2} \mathrm{O}_{4}$ :Eu material after post-annealing treatment under reducing atmosphere at different temperatures. $\mathrm{Eu}_{2} \mathrm{O}_{3}$ and EuS XANES spectra used as reference are reported in inset. Reprinted with permission from Avci et al. ${ }^{[56]}$

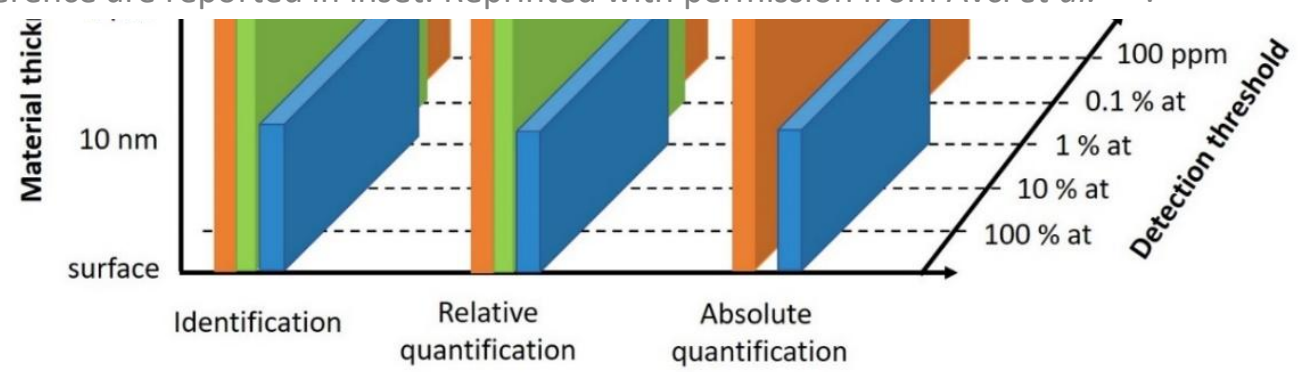

Figure 9 : Comparison of XANES, EPR and XPS methods for the quantification of dopants 
according to the temperature of the reductive treatment. $\mathrm{Eu}^{2+}$ fraction exceed $80 \%$ after a $1200{ }^{\circ} \mathrm{C}$ reductive treatment. Nevertheless, XAS cannot be systematically implemented. Thus, despite recent advances, the precise determination of dopant valence state distribution still remains challenging. The several characteristics for the identification and quantification of dopants and associated investigation domains of these three detailed methods are summarized in Figure 9.

\section{High throughput screening approach: a promising strategy}

High throughput screening approaches allow the investigation of a large amount of compounds. Thus, as no reliable predictive theory exists for the optimization of luminescence properties, this strategy allows to accelerate the discovery of new luminescent by reducing the cost and saving time ${ }^{[62,63]}$.

The implementation of a high throughput screening process includes several steps. The first one corresponds to the identification of factors with the highest impact on targeted properties (e.g. material composition, dopant concentration, synthesis conditions such as temperature, duration or atmosphere...) to reduce the number of possible combinations. The second step consists in defining a strategy for high throughput screening correlated to the material synthesis. To this end, the synthesis of the studied material needs to be straightforward and standardized. Many reported works took advantage of spatial arrangement design ${ }^{[64-67]}$. Pioneer studies on high throughput screening approach, investigating several material compositions, developed systems such as electron beam evaporation for thin films or robotic platforms ${ }^{[62,68-70]}$. Libraries can be obtained and systematically characterized, leading to the discovery or the fast optimization of the desired functional material.

This promising high throughput screening approach can also be adapted to the GRD method presented previously ${ }^{[71]}$. Multiple samples with controlled dopant oxidation states can be synthesized in one pot, which increases significantly the speed of the material discovery with optimized properties. Eu-doped $\mathrm{SrAl}_{2} \mathrm{O}_{4}$ is synthesized following this approach ${ }^{[38]}$. In that respect,

a)

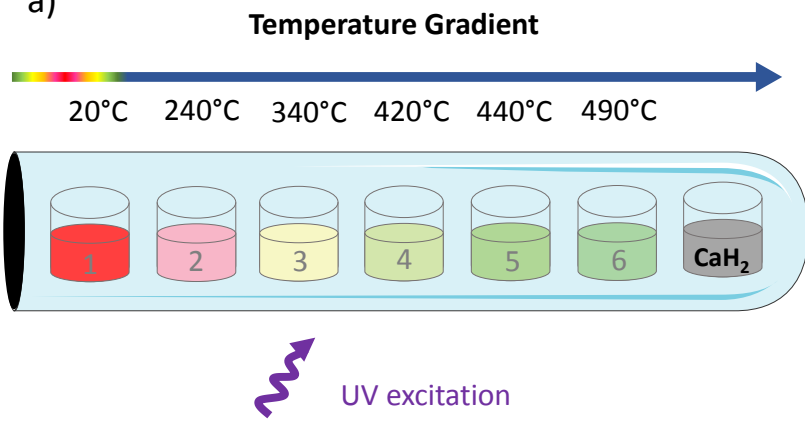

b)

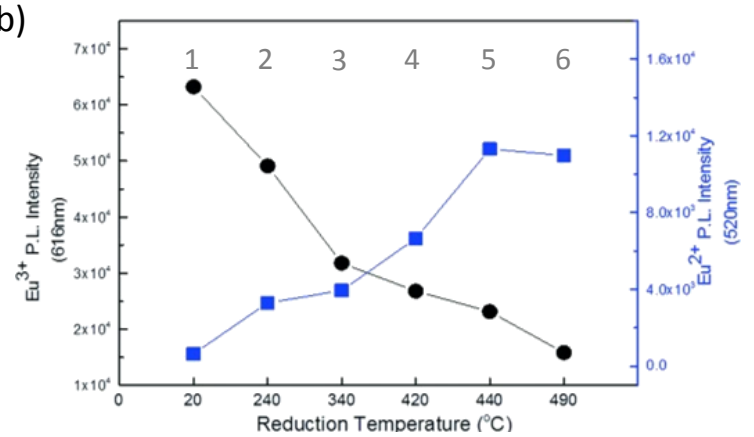

Figure 10: a) Evolution of Eu-doped $\mathrm{SrAl}_{2} \mathrm{O}_{4}$ resulting photoluminescence according to the post treatment temperature and b) Variation of the photoluminescence intensity of $\mathrm{Eu}^{3+}$ and $\mathrm{Eu}^{2+}$ ions inserted in $\mathrm{SrAl}_{2} \mathrm{O}_{4}$ host according to the post treatment temperature. Reprinted with permission from Behrh et al. ${ }^{[38]}$. 
spatially arranged samples are post treated along a temperature gradient with $\mathrm{CaH}_{2}$ used as oxygen getter. Along this gradient, different dopant oxidation states ratios can be reached, and the resulting emission color of the material can be tuned as presented in Figure 10.

This study highlighted the possible adaptation of GRD method into a high throughput screening approach, and could also be more thoroughly investigated and generalized to other luminescent or even non-luminescent materials ${ }^{[72,73]}$. Combination of such approaches with algorithms have also recently emerged ${ }^{[66,74-76]}$ to accelerate the material discovery.

\section{Conclusion}

In this minireview, a collection of approaches for the stabilization and the fine control of different oxidation states for one dopant, such as the modification of atmosphere synthesis, the insertion of a charge compensator, or the gradual reduction/oxidation under temperature gradient, has been highlighted. Although the precise determination of inserted dopants is crucial for the optimization of properties, the quantification remains challenging, especially due to the typically low concentrations of dopants. Furthermore, although the stabilization of several oxidation states of a dopant has been demonstrated in many studies, the mechanism of oxidation remains unclear. Up to now it can be assumed that i) such phenomena could occur with cation diffusion inside the crystal lattice ii) charge balance preservation is governed by the formation (reduction process) or filling (oxidation process) of oxygen vacancies. For that reason, further works is needed to better rationalize the mechanism of reduction / oxidation of dopant ions inserted in the host matrix. To accelerate the discovery of new phosphors, high throughput screening is a promising approach. Such strategy has been applied to the gradual reduction/oxidation of dopants under a temperature gradient. All accessible oxidation states of the dopants can be stabilized and their concentration can be finely controlled. While this minireview mainly focused on luminescence materials, we believe the modulation of valence states of dopants could also be applied and transpose to many other compounds, with for example magnetic, conductive or catalytic properties.

\section{Acknowledgements}

This work was supported by the National Agency for Research (ANR Young Researchers, ANR-16CE08-0003-01, Combi-SSL project).

Keywords: Luminescent material, doped material, dopant valence state, charge balance 


\section{References}

[1] C. Feldmann, T. Jüstel, C. R. Ronda, P. J. Schmidt, Advanced Functional Materials 2003, 13, 511516.

[2] D. R. Gamelin, H. U. Güdel, Acc. Chem. Res. 2000, 33, 235-242.

[3] A. M. Smith, M. C. Mancini, S. Nie, Nature Nanotech 2009, 4, 710-711.

[4] P. Pust, P. J. Schmidt, W. Schnick, Nature Materials 2015, 14, 454-458.

[5] M. Shang, C. Li, J. Lin, Chemical Society Reviews 2014, 43, 1372-1386.

[6] G. Blasse, B. C. Grabmaier, Luminescent Materials, Springer, Berlin, 1994.

[7] Y. Li, S. Qi, P. Li, Z. Wang, RSC Advances 2017, 7, 38318-38334.

[8] H.-T. Sun, J. Zhou, J. Qiu, Progress in Materials Science 2014, 64, 1-72.

[9] B.-M. Liu, Z.-G. Zhang, K. Zhang, Y. Kuroiwa, C. Moriyoshi, H.-M. Yu, C. Li, L.-R. Zheng, L.-N. Li, G. Yang, Y. Zhou, Y.-Z. Fang, J.-S. Hou, Y. Matsushita, H.-T. Sun, Angewandte Chemie International Edition 2016, 55, 4967-4971.

[10] M. Peng, Z. Pei, G. Hong, Q. Su, Journal of Materials Chemistry 2003, 13, 1202-1205.

[11] X. Yu, X. Xu, P. Yang, Z. Yang, Z. Song, D. Zhou, Z. Yin, Q. Jiao, J. Qiu, Materials Research Bulletin 2012, 47, 117-120.

[12] J. Q. Hu, E. H. Song, S. Ye, B. Zhou, Q. Y. Zhang, Journal of Materials Chemistry C 2017, 5, 33433351.

[13] H. Chen, L. Wu, F. Bo, J. Jian, L. Wu, H. Zhang, L. Zheng, Y. Kong, Y. Zhang, J. Xu, Journal of Materials Chemistry C 2019, 7, 7096-7103.

[14] Z. Pei, Q. Su, J. Zhang, Journal of Alloys and Compounds 1993, 198, 51-53.

[15] Y. Pan, M. Wu, Q. Su, Journal of Physics and Chemistry of Solids 2004, 65, 845-850.

[16] Y. Liu, W. Zhuang, Y. Hu, W. Gao, Journal of Rare Earths 2010, 28, 181-184.

[17] L. Wang, L. Zhuang, H. Xin, Y. Huang, D. Wang, Open Journal of Inorganic Chemistry 2015, 5, 1218.

[18] W. Jiang, R. Fu, X. Gu, P. Zhang, A. Coşgun, Journal of Luminescence 2015, 157, 46-52.

[19] J. Hu, E. Song, Y. Zhou, S. Zhang, S. Ye, Z. Xia, Q. Zhang, Journal of Materials Chemistry C 2019, 7, 5716-5723.

[20] J. Lu, Y. Pan, J. Wang, X. Chen, S. Huang, G. Liu, RSC Advances 2013, 3, 4510-4513.

[21] H. F. Brito, M. C. F. C. Felinto, J. Hölsä, T. Laamanen, M. Lastusaari, P. Novák, L. A. O. Nunes, L. C. V. Rodrigues, Physics Procedia 2013, 44, 1-9.

[22] X. Li, Z. Yang, L. Guan, J. Guo, Y. Wang, Q. Guo, Journal of Alloys and Compounds 2009, 478, 684-686.

[23] H. Liu, Y. Hao, H. Wang, J. Zhao, P. Huang, B. Xu, Journal of Luminescence 2011, 131, 24222426.

[24] G. Zhu, Y. Shi, M. Mikami, Y. Shimomura, Y. Wang, Materials Research Bulletin 2014, 50, 405408.

[25] M. G. Brik, Y. X. Pan, G. K. Liu, Journal of Alloys and Compounds 2011, 509, 1452-1456.

[26] Y. Shi, Y. Wang, Y. Wen, Z. Zhao, B. Liu, Z. Yang, Opt. Express, OE 2012, 20, 21656-21664.

[27] Z. Zhang, Y. Wu, X. Shen, Y. Ren, W. Zhang, D. Wang, Optics \& Laser Technology 2014, 62, 6368.

[28] Y. Chen, K. Wu, J. He, Z. Tang, J. Shi, Y. Xu, Z.-Q. Liu, J. Mater. Chem. C 2017, 5, 8828-8835.

[29] M. Peng, Z. Pei, G. Hong, Q. Su, Chemical Physics Letters 2003, 371, 1-6.

[30] Y. Xu, L. Wang, B. Qu, D. Li, J. Lu, R. Zhou, Journal of the American Ceramic Society 2019, 102, 2737-2744.

[31] B. Guo, Z.-W. Zhang, D.-G. Jiang, Y.-N. Li, X.-Y. Sun, Journal of Luminescence 2019, 206, 244249.

[32] W. Lü, H. Xu, M. Hao, H. Wang, X. Kang, Journal of Alloys and Compounds 2018, 752, 231-237.

[33] J. S. Kim, P. E. Jeon, J. C. Choi, H. L. Park, S. I. Mho, G. C. Kim, Appl. Phys. Lett. 2004, 84, 29312933. 
[34] L. Yi, L. Zhou, F. Gong, Y. Lan, Z. Tong, J. Sun, Materials Science and Engineering: B 2010, 172, 132-135.

[35] X. Zhang, Z. Zhu, Z. Guo, Z. Sun, Z. Yang, T. Zhang, J. Zhang, Z. Wu, Z. Wang, Inorg. Chem. Front. 2019, 6, 1289-1298.

[36] X. Chen, J. Zhao, L. Yu, C. Rong, C. Li, S. Lian, Journal of Luminescence 2011, 131, 2697-2702.

[37] H. Barroux, T. Jiang, C. Paul, F. Massuyeau, R. Génois, E. E. Gordon, M.-H. Whangbo, S. Jobic, R. Gautier, Chemistry - A European Journal 2017, 23, 2998-3001.

[38] G. Kaur Behrh, H. Serier-Brault, S. Jobic, R. Gautier, Angewandte Chemie 2015, 127, 1166311665.

[39] R. Gautier, X. Li, Z. Xia, F. Massuyeau, J. Am. Chem. Soc. 2017, 139, 1436-1439.

[40] A. M. Kaczmarek, D. Ndagsi, R. V. Deun, Dalton Trans. 2016, 45, 16231-16239.

[41] F. Wang, X. Liu, Acc. Chem. Res. 2014, 47, 1378-1385.

[42] J. Sokolnicki, E. Zych, Journal of Luminescence 2015, 158, 65-69.

[43] A. A. Martínez, R. Arroyo-Murillo, K. Korthout, D. Poelman, Journal of Alloys and Compounds 2018, 765, 747-752.

[44] V. Singh, G. Sivaramaiah, J. L. Rao, N. Singh, A. K. Srivastava, H. D. Jirimali, J. Li, H. Gao, R. S. Kumaran, P. K. Singh, S. J. Dhoble, Journal of Elec Materi 2016, 45, 2776-2783.

[45] C. Bonardi, C. J. Magon, E. A. Vidoto, M. C. Terrile, L. E. Bausá, E. Montoya, D. Bravo, A. Martín, F. J. López, Journal of Alloys and Compounds 2001, 323-324, 340-343.

[46] D. Gourier, A. Bessière, Suchinder. K. Sharma, L. Binet, B. Viana, N. Basavaraju, K. R. Priolkar, Journal of Physics and Chemistry of Solids 2014, 75, 826-837.

[47] V. Singh, J.-J. Zhu, M. Tiwari, M. Soni, M. Aynayas, S.-H. Hyun, R. Narayanan, M. Mohapatra, V. Natarajan, Journal of Non-Crystalline Solids 2009, 355, 2491-2495.

[48] Materials Chemistry and Physics 2018, 219, 251-257.

[49] Y. Zhong, S. Gai, M. Xia, S. Gu, Y. Zhang, X. Wu, J. Wang, N. Zhou, Z. Zhou, Chemical Engineering Journal 2019, 374, 381-391.

[50] Y. Chen, C. Yang, M. Deng, J. He, Y. Xu, Z.-Q. Liu, Dalton Trans. 2019, 48, 6738-6745.

[51] T. Murata, T. Tanoue, M. Iwasaki, K. Morinaga, T. Hase, Journal of Luminescence 2005, 114, 207-212.

[52] S. A. Acharya, V. M. Gaikwad, S. W. D'Souza, S. R. Barman, Solid State Ionics 2014, 260, 21-29.

[53] Y. Zhang, J. Chen, C. Xu, Y. Li, H. Jin Seo, Physica B: Condensed Matter 2015, 472, 6-10.

[54] Z. An, W. Liu, Y. Song, X. Zhang, R. Dong, X. Zhou, K. Zheng, Y. Sheng, Z. Shi, H. Zou, Journal of Materials Chemistry C 2019, 7, 6978-6985.

[55] C. Yang, Z. Zhang, G. Hu, R. Cao, X. Liang, W. Xiang, Journal of Alloys and Compounds 2017, 694, 1201-1208.

[56] N. Avci, K. Korthout, M. A. Newton, P. F. Smet, D. Poelman, 2012, 10.

[57] P. J. R. Montes, V. C. Teixeira, D. A. B. Barbosa, C. W. A. Paschoal, M. V. dos S. Rezende, Journal of Alloys and Compounds 2017, 708, 79-83.

[58] P. Dai, Q. Wang, M. Xiang, T.-M. Chen, X. Zhang, Y.-W. Chiang, T.-S. Chan, X. Wang, Chemical Engineering Journal 2020, 380, 122508.

[59] S. M. Loureiro, Y. Gao, V. Venkataramani, Journal of the American Ceramic Society 2005, 88, 219-221.

[60] X.-Y. Sun, Z.-H. Xiao, Y.-T. Wu, X.-G. Yu, Q.-L. Hu, Y. Yuan, Q. Liu, C. Struebing, Z. Kang, Journal of the American Ceramic Society 2018, 101, 4480-4485.

[61] R. Génois, S. Jobic, G. Ouvrard, F. Massuyeau, R. Gautier, Applied Materials Today 2020, 20, 100643.

[62] E. Danielson, J. H. Golden, E. W. McFarland, C. M. Reaves, W. H. Weinberg, X. D. Wu, Nature 1997, 389, 944-948.

[63] E. W. McFarland, W. H. Weinberg, Trends in Biotechnology 1999, 17, 107-115.

[64] E. Danielson, M. Devenney, D. M. Giaquinta, J. H. Golden, R. C. Haushalter, E. W. McFarland, D. M. Poojary, C. M. Reaves, W. H. Weinberg, X. D. Wu, Science 1998, 279, 837-839. 
[65] T.-S. Chan, C.-C. Kang, R.-S. Liu, L. Chen, X.-N. Liu, J.-J. Ding, J. Bao, C. Gao, J. Comb. Chem. 2007, 9, 343-346.

[66] C. Kulshreshtha, A. K. Sharma, K.-S. Sohn, J. Comb. Chem. 2008, 10, 421-425.

[67] L. Chen, C.-I. Chu, K.-J. Chen, P.-Y. Chen, S.-F. Hu, R.-S. Liu, Luminescence 2011, 26, 229-238.

[68] W. B. Park, N. Shin, K.-P. Hong, M. Pyo, K.-S. Sohn, Advanced Functional Materials 2012, 22, 2258-2266.

[69] L. Chen, K.-J. Chen, C.-C. Lin, C.-I. Chu, S.-F. Hu, M.-H. Lee, R.-S. Liu, J. Comb. Chem. 2010, 12, 587-594.

[70] L. Chen, A. Luo, Y. Zhang, F. Liu, Y. Jiang, Q. Xu, X. Chen, Q. Hu, S.-F. Chen, K.-J. Chen, H.-C. Kuo, ACS Comb. Sci. 2012, 14, 636-644.

[71] H. Yuan, R. Génois, E. Glais, F. Chen, Q. Shen, L. Zhang, E. Faulques, F. Massuyeau, R. Gautier, Journal of Solid State Chemistry 2020, 288, 121367.

[72] T. Jiang, X. Li, M. Bujoli-Doeuff, E. Gautron, L. Cario, S. Jobic, R. Gautier, Inorg. Chem. 2016, 55, $7729-7733$.

[73] X.-D. Xiang, I. Takeuchi, Combinatorial Materials Synthesis, CRC Press, 2003.

[74] K.-S. Sohn, J. M. Lee, N. Shin, Advanced Materials 2003, 15, 2081-2084.

[75] K.-S. Sohn, D. H. Park, S. H. Cho, B. I. Kim, S. I. Woo, J. Comb. Chem. 2006, 8, 44-49.

[76] Y. S. Jung, C. Kulshreshtha, J. S. Kim, N. Shin, K.-S. Sohn, Chem. Mater. 2007, 19, 5309-5318.

\section{Biographical information}

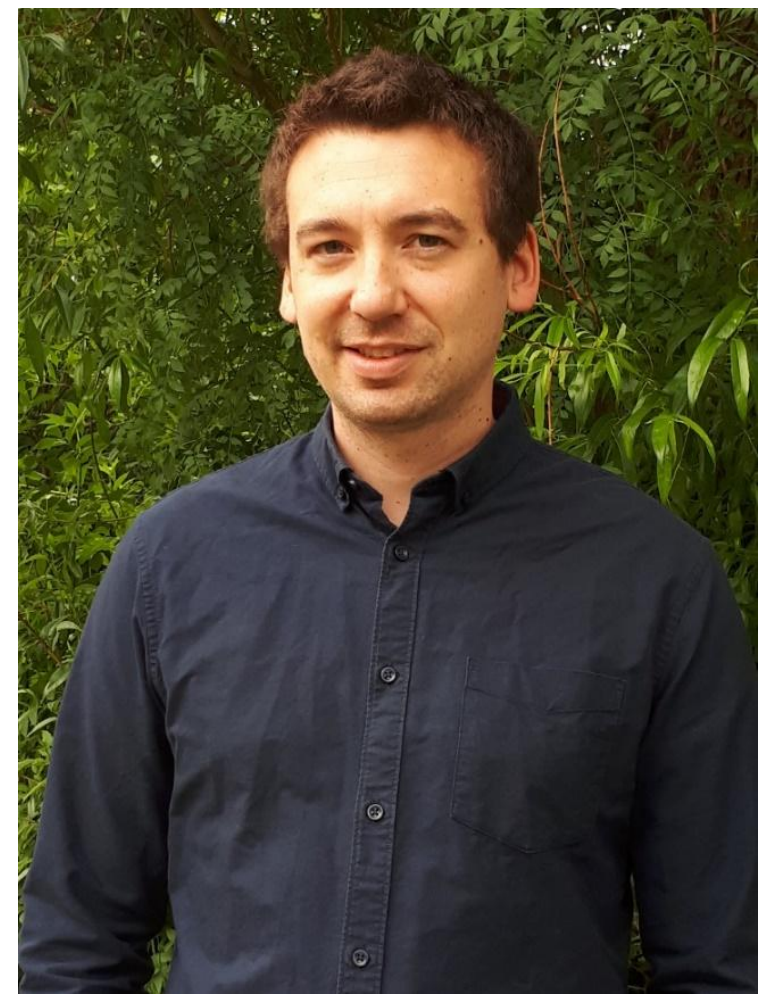

Romain Gautier is a research scientist at Centre National de la Recherche Scientifique (CNRS) in the Institut des Matériaux Jean Rouxel. He obtained a Ph.D. degree from Ecole Nationale Supérieure de Chimie de Rennes in inorganic and materials chemistry in 2010 and, then, moved to Northwestern University as a postdoc in the group of Prof. Poeppelmeier. He is the recipient of the CNRS Bronze medal and the National Chinese Award of "1000 Young Talents Program". His current research interests include the design, synthesis and characterization of new inorganic and hybrid materials with properties of second harmonic generation and luminescence. 


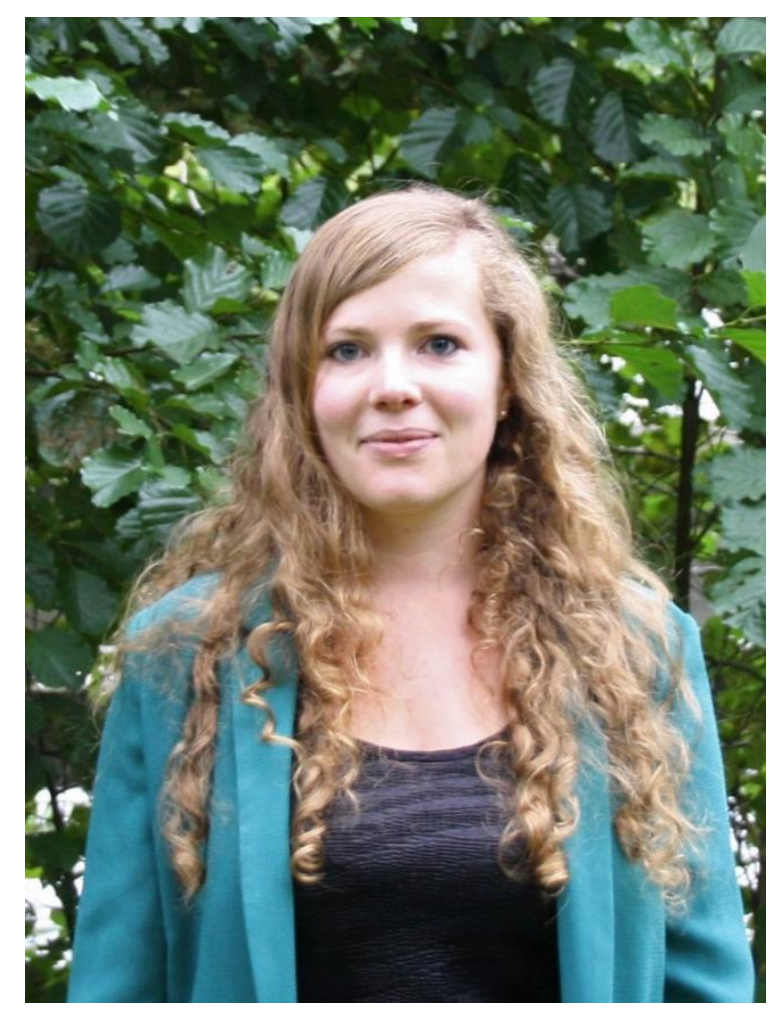

Estelle Glais obtained her Ph.D degree from Sorbonne Université in 2018 under the supervision of Pr. Corinne Chanéac and Dr. Bruno Viana. Her PhD researches were focused on Nanostructures with optical and thermal properties for the design of "Nanothermometers". She is currently a postdoctoral fellow in Institut des Matériaux Jean Rouxel in Nantes, working on the development of new high throughput approaches for the accelerated discovery of luminescent materials. 